\title{
Vertebroplasty and Kyphoplasty for Osteoporotic Vertebral Fractures: What Are the Latest Data?
}

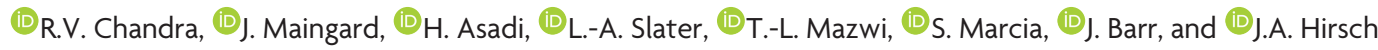

\begin{abstract}
SUMMARY: Osteoporotic vertebral compression fractures frequently result in significant morbidity and health care resource use. For patients with severe and disabling pain, vertebral augmentation (vertebroplasty and kyphoplasty) is often considered. Although vertebroplasty was introduced $>30$ years ago, there are conflicting opinions regarding the role of these procedures in the treatment of osteoporotic vertebral compression fractures. This review article updates clinicians on the published prospective randomized controlled data, including the most recent positive trials that followed initial negative trials in 2009. Analysis of multiple national claim datasets has also provided further insight into the utility of these procedures. Finally, we considered the recent recommendations of national organizations and medical societies that advise on the use of vertebral augmentation procedures for osteoporotic vertebral compression fractures.
\end{abstract}

ABBREVIATIONS: NRS = numeric rating scale; PMMA = polymethylmethacrylate; QUALEFFO = Quality of Life Questionnaire of the European Foundation for Osteoporosis; $\mathrm{RCT}=$ randomized controlled trial; RDQ = Roland Morris Disability Questionnaire; VAS = Visual Analog Scale; VCF = vertebral compression fracture

O steoporosis and low bone mass affect $>50$ million people in the United States: Every other person older than 50 years of age has low bone mass or osteoporosis. ${ }^{1}$ The major sources of morbidity and community health care costs from osteoporosis are related to fractures. By 50 years of age, the remaining lifetime fracture risk is 1 in 2 for women and 1 in 5 for men. ${ }^{2}$ By 2025, >3 million osteoporotic fractures and $\$ 25$ billion in related health care costs will occur in the United States. ${ }^{3}$ Of these, vertebral compression fractures (VCFs) will account for one-quarter of osteoporotic fractures. ${ }^{3}$

Some osteoporotic VCFs result in minimal or mild pain. Symptoms typically subside during 6-8 weeks as healing occurs. For such patients, medical management with analgesics or limiting activities/bed rest, back braces, and physical therapy or a combination of these are the mainstay of treatment. Patients with

From the Interventional Neuroradiology Unit (R.V.C., H.A., L.-A.S.), Monash Imaging, Monash Health, Melbourne, Victoria, Australia; Faculty of Medicine, Nursing and Health Sciences (R.V.C., L.-A.S.), Monash University, Melbourne, Victoria, Australia; Interventional Neuroradiology Service (J.M., H.A.), Department of Radiology, Austin Hospital, Melbourne, Victoria, Australia; School of Medicine, Faculty of Health (H.A.), Deakin University, Waurn Ponds, Victoria, Australia; Neuroendovascular Program (T.-L.M., J.A.H.), Massachusetts General Hospital, Harvard Medical School, Boston, Massachusetts; Department of Radiology (S.M.), SS. Trinità Hospital, Cagliari, Italy; and Interventional Neuroradiology (J.B.), University of Texas Southwestern Medical Center, Dallas, Texas.

Please address correspondence to Ronil V. Chandra, FRANZR CCINR, Interventional Neuroradiology Unit, Monash Imaging, Monash Health, Monash University, 246 Clayton Rd, Melbourne, Victoria 3168, Australia; e-mail: ronil.chandra@monash.edu

- Indicates open access to non-subscribers at www.ajnr.org

http://dx.doi.org/10.3174/ajnr.A5458 more severe pain seek medical attention or require hospitalization. Annually, $>60,000$ office visits and $>70,000$ admissions occur from osteoporotic VCFs in the United States. ${ }^{4,5}$ For these patients, medical management often involves bed rest. As few as 2 days of bed rest lead to bone mass loss ${ }^{6}$; by 1 week, the rate of bone loss is 50 times the normal age-related rate. ${ }^{7}$ After 10 days of bed rest, $15 \%$ of aerobic capacity and lower extremity strength is lost, ${ }^{8}$ equivalent to 10 years of age-related loss. ${ }^{8}$ Adding narcotic anesthesia and the associated adverse effects of sedation, nausea, and constipation further increases physical deconditioning and fall risk and prolongs recovery. After hospitalization, $>50 \%$ require ongoing care ${ }^{4}$; chronic pain occurs in $40 \% .{ }^{9}$ Thus, while medical management is widely used, there are significant negative effects.

In patients with severe pain, vertebral augmentation (vertebroplasty and/or kyphoplasty) may be considered. In general, patients with severe and disabling back pain with correlating physical examination and advanced imaging findings (MR imaging bone marrow edema or bone-scan/SPECT/CT uptake) are selected for treatment. These minimally invasive procedures involve injection of cement (polymethylmethacrylate [PMMA]) into the VCF. Kyphoplasty involves the additional step of cavity creation; most typically, a balloon tamp is inflated to create a cavity into which PMMA is injected. Both treatments may reduce pain and disability and improve alignment.

Although $>3000$ articles have been published on vertebral augmentation, there remains debate on whether it is effective. Our aim was to update clinicians with a focused review of published prospective randomized controlled trials (RCTs) of verte- 
broplasty and kyphoplasty for osteoporotic fractures. We considered the inclusion of patients in these trials by fracture age: acute ( $<6$ weeks), subacute (6-12 weeks), and chronic ( $>12$ weeks). We also considered the insights provided by national claims data and recent recommendations of national organizations and medical societies.

\section{Early Observational Data}

Successful small European series led to Jensen et al ${ }^{10}$ introducing vertebroplasty to the United States in 1993 and their publication in the American Journal of Neuroradiology in 1997. Twenty-nine patients with 47 painful osteoporotic VCFs were included. Twentysix $(90 \%)$ reported pain relief and improved mobility within 24 hours. ${ }^{10}$ Publication of several series followed, which were pooled to more robustly assess clinical outcomes. An analysis of vertebroplasty for osteoporotic VCFs from 1989 to 2004 included 2086 patients. ${ }^{11}$ Nineteen studies reported pain outcomes; there was significant reduction of pain after vertebroplasty (mean Visual Analog Scale [VAS] score, 8.1-2.6; $P<.001)$. Serious complications occurred in $<1 \%$. Similar outcomes were described for kyphoplasty; 1710 patients were pooled. ${ }^{12}$ There was significant reduction of the VAS score after treatment (weighted mean difference, $-5.11 ; 95 \% \mathrm{CI},-5.72$ to -4.49$)$. Alignment was also improved, anterior vertebral height was increased, and kyphosis was reduced. ${ }^{12}$

In 2007, encouraging preliminary data led medical societies to endorse vertebral augmentation as safe and effective for painful osteoporotic VCFs refractory to medical management. ${ }^{13}$ However, there were no RCT data, and there were concerns due to the improvement in back pain for most patients, regression to the mean for patients with severe pain, ${ }^{14}$ and the influence of the placebo effect. ${ }^{15}$ Further evidence from prospective RCTs was required.

\section{Early RCTs}

The Vertebroplasty for Painful Chronic Osteoporotic Vertebral Fractures (VERTOS) trial published in 2007 was the first early prospective RCT of vertebroplasty compared with medical management for osteoporotic VCFs. ${ }^{16}$ Inclusion criteria were 50 years of age or older, invalidating pain, subacute and chronic fracture age (6-24 weeks), tenderness on examination, and MR imaging bone marrow edema. Thirty-four patients were enrolled ( $n=18$ in vertebroplasty, $n=16$ in medical management). At 24 hours, there was significant improvement in the VAS score after vertebroplasty (4.7 versus 7.1; difference, -2.4 ; $95 \% \mathrm{CI}-3.7$ to -1.0 ). At 2 weeks, this was no longer significant. Fourteen (88\%) of 16 patients in the medical management arm crossed over to vertebroplasty; no long-term follow-up was possible.

The Fracture Reduction Evaluation (FREE) trial from early 2009 is the only multicenter prospective RCT that compared kyphoplasty with medical management for VCFs. ${ }^{17}$ Inclusion criteria were 21 years of age or older, moderate back pain $(\geq 4 / 10$ on the numeric rating scale [NRS], acute and subacute fracture age [ $<3$ months]), focal tenderness, and MR imaging bone marrow edema. Three hundred patients were enrolled ( $n=149$ in kyphoplasty, $n=151$ in medical management). At 1 month, the primary end point was positive: significantly greater improve- ment in Short-Form-36 physical component summary scores in the kyphoplasty arm (difference, 5.2 points; 95\% CI, 2.9-7.4; $P<$ $.001)$. These improvements were durable to 6 months. Patients in the kyphoplasty arm gained 60 days without restricted activity and bed rest.

The main limitation of the FREE trial was the lack of blinding, which overestimates treatment benefit due to the placebo response. ${ }^{18}$ Moreover, 4 patients had nonosteoporotic fractures. The FREE investigators later reported 2-year outcome data. There was durable reduction in back pain NRS scores but no difference in the Short-Form-36 or Roland Morris Disability Questionnaire (RDQ) scores at 24 months. ${ }^{19}$ Anatomic outcomes were durable: The $27 \%$ anterior height restoration and $3.3^{\circ}$ of kyphosis correction gained was maintained. ${ }^{20}$

Rousing et al $^{21}$ published a small RCT in mid-2009 designed to compare vertebroplasty with medical management. Inclusion criteria were 65 years of age or older, intractable back pain, and fractures of $<8$ weeks with plain radiographic confirmation. Forty-nine patients were enrolled ( $n=25$ in vertebroplasty, $n=$ 24 in medical management). The primary outcome was the 3 -month VAS score. Both groups had similar VAS scores at 3 months $(P=.33)$. However, there was a reduction in the VAS within 24 hours (VAS 7.7 versus $2.0, P<.01$ ) and shorter hospital stay ( 7.6 days versus 11.7 days, $P=.01$ ) after vertebroplasty. Limitations included the small single-center nature and lack of baseline VAS for $27 \%$. A later post hoc analysis favored vertebroplasty at 1 month (VAS 3.5 versus $6.4, P<.01$ ). ${ }^{22}$

Although the FREE trial provided data to support vertebral augmentation, there remained questions regarding the placebo effect. In August 2009, 2 double-blind multicenter RCTs comparing vertebroplasty with a sham procedure were published in the New England Journal of Medicine. ${ }^{23,24}$ The Investigational Vertebroplasty Safety and Efficacy Trial (INVEST) was designed to compare vertebroplasty with a sham procedure for patients with osteoporotic VCFs. ${ }^{24}$ Inclusion criteria were 50 years of age or older, moderate and severe back pain ( $\geq 3 / 10$ points), and fracture age $<1$ year confirmed by examination and spine imaging (either plain radiographs or MR imaging). A total of 131 patients were enrolled ( $n=68$ in vertebroplasty, $n=63$ in sham procedures). In both treatment arms, bupivacaine was injected onto the periosteum. In the sham procedure, vertebroplasty was simulated with verbal cues, manual palpation to simulate needle placement, and simulation of the PMMA smell. Baseline fracture age was 16 weeks and 20 weeks in the vertebroplasty and sham procedure arms, respectively.

The primary end point was back pain NRS and RDQ scores at 1 month. At 1 month, there was no difference in back pain NRS $(P=.19)$ or RDQ scores $(P=.49)$. There were also no statistically significant differences in secondary outcome measures of pain, disability, and quality of life. Notably, there was a trend toward a higher rate of clinically meaningful improvement in pain $(30 \%$ reduction) in the vertebroplasty group (64\% versus $48 \%, P=$ $.06)$. By 3 months, $43 \%$ of patients crossed over to vertebroplasty; no longer term comparisons were possible.

There were limitations to INVEST: Forty percent of patients had fractures of $<3$ months, while $36 \%$ had fractures of $>6$ months. Thus, the trial examined acute, subacute, and chronic AJNR Am J Neuroradiol 39:798-806 May 2018 www.ajnr.org 
VCFs. In addition, because MR imaging edema was not a specific requirement, patients were included after plain radiography. However, there may have been adjacent radiographically occult fractures that could have been identified if MR imaging was performed. In addition, enrollment was slow; 1813 patients were screened, 300 declined, and 131 enrolled during 4 years at 11 centers in the United States, United Kingdom, and Australia. Although these centers were chosen on the basis of established vertebroplasty services, INVEST recruited an average of 3 patients per center per year, and sample size estimates were reduced from 249 to 166 . In addition, there was a high proportion of patients with Workers Compensation claims. ${ }^{25}$

Buchbinder et $\mathrm{al}^{23}$ published another multicenter doubleblind prospective RCT comparing vertebroplasty with a sham procedure. Inclusion criteria were back pain, fracture age $<1$ year, and MR imaging-confirmed fracture line and/or edema. Seventyeight patients were enrolled ( $n=38$ vertebroplasties, $n=40$ sham procedures). In both treatment arms, a 13-ga needle was inserted to the periosteum. In the sham procedure arm, vertebroplasty was simulated with gentle tapping of the needle with the hammer, rotation of the imaging intensifier, and PMMA preparation. ${ }^{26}$ Baseline fracture age was 9 weeks and 9.5 weeks in the vertebroplasty and sham procedure arms, respectively.

The primary outcome was back pain NRS score at 3 months. At 3 months, there was no difference in NRS scores, with no difference at 1 week, 3 months, or 6 months. Additional secondary outcome measures of pain, disability, and quality of life also did not differ.

There were limitations: Thirty-two percent had fractures of $<6$ weeks' duration, and one-quarter of patients had fractures between 3 and 12 months (mainly 3-6 months). Thus, acute, subacute, and chronic fractures were included, with limitations similar to those in INVEST. Moreover, a physical examination requirement was not included. From the 468 patients screened, 141 declined and 78 were enrolled during 4 years at 4 Australian centers. Most (68\%) were recruited at 1 center; 2 sites enrolled 5 patients. Thus, outcomes may be weighted to this single center. Similar to INVEST, the investigators terminated the trial before reaching the sample size of 82 patients per group for 24-month outcomes; they did achieve their calculated sample size of 24 per group, considered to have $80 \%$ power to show a short-term treatment advantage of vertebroplasty. ${ }^{23}$

The VERTOS II study followed, another large prospective multicenter RCT designed to compare early vertebroplasty with medical management. ${ }^{27}$ Inclusion criteria were 50 years of age or older, moderate back pain (VAS $\geq 5$ ), fracture age ( $<6$ weeks), focal tenderness, and MR imaging bone edema. ${ }^{28}$ Two hundred two patients were enrolled ( $n=101$ for vertebroplasty, $n=101$ for medical management). At 1 month, the primary end point was positive: There was a significant improvement in the VAS score in the vertebroplasty arm (VAS, 2.5 versus $4.9 ; P<.001$ ), which was durable at 1 year. Patients achieved pain relief almost 3 months faster and gained 120 pain-free days during a year. There were also improvements for secondary outcomes of the RDQ scores $(P<$ $.001)$ and Quality of Life Questionnaire of the European Foundation for Osteoporosis (QUALEFFO) scores $(P<.001)$ favoring vertebroplasty.
The main limitation of the VERTOS II trial was the lack of blinding. Further post hoc analysis of the medical cohort revealed that $60 \%$ achieved sufficient (VAS $\leq 3$ ) pain relief by 12 months, with most within 3 months. ${ }^{9}$ There were no predictors to identify the $40 \%$ who developed chronic pain. This finding led the investigators to postulate that vertebroplasty may be justified for patients without sufficient pain relief after 3 months of medical management, setting the stage for further trials.

Debate persisted about whether vertebroplasty for recent fractures ( $\leq 6$ weeks) or severe pain (NRS score $\geq 8$ ) provided benefit. Thus, data from INVEST and the trials of Buchbinder et $\mathrm{al}^{23,26}$ were pooled. Across these trials, $27 \%(n=57)$ had recent-onset ( $\leq 6$ weeks) pain and $47 \%(n=99)$ had severe (NRS $\geq 8)$ pain. There was no difference in pain and disability scores at 1 month. ${ }^{29}$ Statistical power was increased by pooling the data. However, limitations of the INVEST and Buchbinder trials remained.

In 2011, Farrokhi et $\mathrm{al}^{30}$ published another RCT of vertebroplasty compared with medical management for osteoporotic VCFs. Inclusion criteria were severe pain, fracture age 4 weeks to 1 year, focal tenderness, MR imaging edema or unhealed fracture cleft, and failure of medical management for 4 weeks. Eighty-two patients were enrolled ( $n=40$ in vertebroplasty, $n=42$ in medical management). There was reduction in the VAS score in the vertebroplasty arm at 1 week (difference, $-3.1 ; P<.001$ ) and improvement in quality of life measures. All patients in the vertebroplasty arm were ambulatory after 24 hours compared with $2 \%$ after medical management. There was a gain in vertebral body height (mean, $8 \mathrm{~mm}$ ) and reduction of kyphosis (mean, $8^{\circ}$ ) after vertebroplasty. Blasco et $\mathrm{al}^{31}$ followed with their trial of vertebroplasty compared with medical management for osteoporotic VCFs in 2012. Inclusion criteria were moderate pain (VAS $\geq 4$ ), fracture age $<1$ year, and MR imaging edema or increased uptake on bone scans. One hundred twenty-five patients were enrolled ( $n=64$ in vertebroplasty, $n=61$ in medical management). The mean duration of back pain was 4.7 months; 6 (5\%) had fractures of $<6$ weeks. At 2 months, there was greater VAS improvement in the vertebroplasty arm compared with the medical arm $(P=$ .017). Rescue anesthesia (intrathecal infusion) was required in 5\% of the vertebroplasty arm compared with $25 \%$ of the medical arm $(P=.002)$. Both groups had similar improvement in VAS and QUALEFFO scores by 12 months. Limitations include the lack of treatment blinding, the $11 \%$ crossover rate to vertebroplasty, and the high loss of follow-up rate (24\%).

\section{Recent Prospective Randomized Controlled Data}

During these early trials, there remained ongoing doubt regarding the influence of the placebo effect. The sham procedure trials were designed to minimize the placebo effect, but patients with acute, subacute, and chronic fractures causing both moderate and severe pain were enrolled. Moreover, there is now increased recognition of placebo, nocebo, and the concept of active control treatments (such as periosteal local anesthetic injection in the early RCTs) that contribute to success or failure of pain relief. ${ }^{32}$ In addition, clinicians performing vertebral augmentation recognized that older patients with severe pain from recent fracture, particularly those admitted to the hospital, may form a subgroup for which 


\begin{tabular}{|c|c|c|c|}
\hline & Trials of Buchbinder et $\mathrm{al}^{23,26}$ & INVEST $^{24}$ & VAPOUR $^{33}$ \\
\hline Total enrollment (No.) & 78 & 131 & 120 \\
\hline Age (yr) inclusion threshold & None & 50 & 60 \\
\hline Mean (SD) age (yr) & $76.6(12.1)$ & $73.8(9.4)$ & $80.5(7)$ \\
\hline NRS pain score inclusion threshold & None & $\geq 3$ & $\geq 7$ \\
\hline No. (\%) with severe pain & $38(49 \%)$ NRS $\geq 8 / 10$ & $61(47 \%) \mathrm{NRS} \geq 8 / 10$ & $120(100 \%)$ NRS $\geq 7 / 10$ \\
\hline Fracture age (wk) threshold & $<52$ & $<52$ & $<6$ \\
\hline Mean (SD) fracture age (wk) & $11.7(11.1)$ & $22.5(16.3)$ & $3(2)$ \\
\hline No. (\%) fractures <6-weeks & $31(40 \%)$ & $26(20 \%)$ & $120(100 \%)$ \\
\hline Advanced imaging (MRI or SPECT/CT) required? & Yes & No & Yes \\
\hline Hospitalized patients & NR & 0 & $57 \%$ \\
\hline Mean (SD) PMMA volume (mL) & $2.8(1.2)$ & NR & $7.5(2.8)$ \\
\hline Primary end point & Mean NRS pain at $3 \mathrm{mo}$ & Mean NRS pain at 1 mo & $\%$ NRS pain $<4 / 10$ at $2 \mathrm{wk}$ \\
\hline Primary outcome & No difference & No difference & Vertebroplasty superior \\
\hline
\end{tabular}

Note:-NR indicates not reported.

vertebroplasty may be of greater benefit. These patients have been included in the recent RCTs.

The Vertebroplasty for Acute Painful Osteoporotic fractures (VAPOUR) trial was designed to compare early vertebroplasty with a sham procedure for patients with severe pain. ${ }^{33}$ Inclusion criteria were 60 years of age and older, severe back pain (NRS $\geq$ 7 ), fracture age $<6$ weeks, and MR imaging edema or SPECT/CT uptake within 1 week. One hundred twenty patients were enrolled ( $n=61$ in vertebroplasty, $n=59$ in sham procedures). The sham procedure was identical to that in INVEST except that a local anesthetic was injected into the subcutaneous tissues, and the PMMA kit did not emit a smell. There was no difference in the baseline pain NRS score; baseline fracture age was also similar (2.8 versus 2.4 weeks).

The primary end point was the proportion of patients whose NRS pain scores were reduced to $<4$ by 14 days. There was a significant treatment advantage in the vertebroplasty arm $(44 \%$ versus $21 \%, P=.011)$ that was durable to 6 months. There were greater reductions in RDQ and QUALEFFO scores favoring vertebroplasty. Notably, $57 \%$ of patients were hospital in-patients; the median length of admission was reduced by 5.5 days after vertebroplasty. Anatomic outcomes were also superior: $30 \%$ greater vertebral height preservation compared with the sham procedure.

The limitations of VAPOUR include the bias toward a single center, with $85 \%$ performed at 1 of 4 recruiting centers. ${ }^{34}$ Moreover, 8 of 120 patients did not have the 14-day outcome measure due to delirium, being uncontactable, or revoking consent. However, even if these patients ( 6 in the vertebroplasty arm) were considered treatment failures, the primary outcome remained significant.

VAPOUR had some important differences compared with the earlier sham procedure trials (Table), being the first sham procedure RCT that focused on stringent patient selection. Although all patients had fracture ages of $<6$ weeks, most ( $80 \%$ ) had fractures of $<3$ weeks. Second, many (57\%) were hospitalized and had vertebroplasty $<7$ days from admission. Third, PMMA volumes (mean, $7.5 \mathrm{~mL}$ ) were much greater than in the trial of Buchbinder et al. ${ }^{23}$ Although this trial had specified that 3-4 mL of PMMA would be injected, ${ }^{26}$ many patients received less PMMA (mean, $2.8 \mathrm{~mL}$ ). The INVEST trial investigators did not record PMMA volumes. ${ }^{35}$ There are conflicting data on whether higher cement volume or the percentage of vertebral body filled is associated with higher rates of pain relief, with some investigators reporting no association, ${ }^{36}$ while others reported a positive cement volume-clinical response association. ${ }^{37,38}$ In addition, the sham procedure in VAPOUR involved subcutaneous local anesthetic injection, closer to a true placebo, ${ }^{32}$ compared with the previous trials that used periosteal local anesthetic, an active control treatment that could relieve secondary facet joint pain. ${ }^{39}$

Additional small prospective open-label trials were also published in 2016. Yang et $\mathrm{al}^{40}$ examined elderly patients with early vertebroplasty. Inclusion criteria were 70 years of age and older and moderate and severe pain (VAS $\geq 5$ ) with MR imaging edema. One hundred thirty-five patients were enrolled ( $n=66$ in vertebroplasty, $n=69$ in medical management). In the vertebroplasty arm, vertebroplasty was performed at a mean of 8.4 days after symptom onset, with all patients treated $<3$ weeks from onset. There was significantly greater improvement in the VAS in the vertebroplasty arm from day 1 , which was durable to 1 year. There were improvements in the Oswestry Disability Index and QUALEFFO scores. Limitations included the lack of treatment blinding, the $12 \%$ crossover rate, and the small single-institution result limiting generalizability. Leali et $\mathrm{al}^{41}$ examined postmenopausal women with 1 osteoporotic VCF. Inclusion criteria were fracture age $<6$ weeks and MR imaging edema. Four hundred women were enrolled ( $n=200$ in vertebroplasty, $n=200$ in medical management). Baseline fracture age and the VAS in each arm were not reported. Although there was improvement in the vertebroplasty arm at 1 day, there was no difference in the VAS and Oswestry Disability Index at $\geq 6$ weeks. Limitations included the significant paucity of data reported and the lack of treatment blinding.

There is also interest in whether chronic unhealed fractures respond to vertebroplasty as examined by Chen et al in $2014 .{ }^{42}$ Inclusion criteria were persistent severe pain for $>3$ months and MR imaging edema. A total of 96 patients were enrolled ( $n=46$ in vertebroplasty, $n=50$ on medical management); the mean fracture age was 7 months. From 1 week, there were significantly greater reductions in the VAS score in the vertebroplasty arms that were durable at 1 month, 3 months, 6 months, and 1 year. Similar improvements were evident in RDQ scores. By 1 year, $85 \%$ of the patients with vertebroplasty had complete pain relief compared with $35 \%$ in the medical arm $(P<.001)$. Similar limi- 
tations remain: the lack of treatment blinding and the small single-center design.

\section{Upcoming Evidence}

Currently, there remain multiple ongoing trials of vertebral augmentation for osteoporotic fractures. The VERTOS investigators initiated VERTOS IV using the same inclusion criteria as VERTOS II but comparing vertebroplasty with a sham procedure. Enrollment commenced in 2011, with the aim of randomizing 180 patients; results have not been published. ${ }^{43}$ The Vertebroplasty Compared with a Sham-Procedure for Painful Acute Osteoporotic Vertebral Fractures (VOPE) trial is a smaller trial comparing vertebroplasty with periosteal lidocaine injection, which enrolled 52 patients; results have not been published. ${ }^{44}$ VERTOS V will be an important trial for patients with chronic unhealed fractures, comparing vertebroplasty with a sham procedure for patients 50 years of age or older with persistent moderate pain (VAS $\geq 5$ ) from a chronic ( $\geq 3$ months) VCF. ${ }^{45}$

\section{Safety Outcomes}

Major symptomatic procedural complications from vertebroplasty are significant hemorrhage or vascular injury, spine infection, symptomatic cement pulmonary emboli, symptomatic hemothorax or pneumothorax, new procedure-related fractures, permanent neurologic deficits occurring within 30 days or requiring an operation, and death. ${ }^{46}$ Across the RCTs reviewed, these major complications occurred in $<1 \%$, with no procedural mortality. All procedure-related fractures were managed conservatively. ${ }^{33}$ Osteomyelitis occurred in 1 patient who did not receive prophylactic antibiotics, ${ }^{23}$ and a symptomatic cement leak occurred in 1 patient, requiring decompressive surgery with neurologic recovery. ${ }^{30}$ These results have translated to clinical practice: In a large population-based study of elderly patients $(n=1773)$, no spinal cord injury or procedural death occurred. ${ }^{47}$

Cement leakage outside the vertebra is common when assessed with CT (72\% in VERTOS II). ${ }^{28}$ Most occur via the end plates, into the disc or local adjacent veins; symptomatic leakage is very rare. During kyphoplasty, compacted bone at the periphery of the cavity is created by balloon tamp inflation, which allows cement injection at lower pressure and higher viscosity, which reduces the rate of leaks. ${ }^{48}$ Higher rates of leak are likely with cortical disruption or fracture clefts, use of low-viscosity cement, and higher volume injections. ${ }^{48}$

Vertebral augmentation does not increase the baseline risk of new VCFs. Overall, 1 in 5 patients develop a new VCF within 12 months of the initial VCF; the risk is higher in patients with multiple VCFs. ${ }^{49}$ Two meta-analyses of published prospective trials found no difference in subsequent VCF risk between the medical management and vertebroplasty cohorts ${ }^{50,51}$; baseline low bone mineral density is most consistently associated with increased subsequent VCF risk. ${ }^{52}$

Medical management for VCFs is not always risk-free: Four patients in 2 trials developed spinal cord compression. ${ }^{33,40}$ Three underwent an operation with neurologic recovery; the other remained paraplegic. These occurrences relate to further VCF height loss. In VAPOUR, in almost 50\%, further height loss occurred by 6 months in the sham procedure arm. ${ }^{33}$ The rates of pneumonia and venous thrombosis were not consistently reported but occurred in $12 \%$ in 1 trial. $^{40}$ The complications associated with narcotic anesthesia are not reported, but there is growing concern regarding narcotic anesthesia in elderly patients.

\section{Vertebroplasty or Kyphoplasty}

Although many RCTs have been published comparing vertebroplasty or kyphoplasty with medical management, there have been few prospective RCTs comparing the safety and efficacy of vertebroplasty with kyphoplasty. The largest RCT was the Kyphoplasty and Vertebroplasty in the Augmentation and Restoration of Vertebral Body Compression Fractures (KAVIAR) trial, which was designed to detect a difference in subsequent radiographic fractures. ${ }^{53}$ Although this trial was terminated early due to limited enrollment, 361 patients completed 1-month follow-up ( $n=181$ vertebroplasty, 180 kyphoplasty procedures). The mean procedural duration was longer with kyphoplasty, with no difference in clinical outcome or symptomatic complications. Similar results have been reported in 2 smaller prospective RCTs. ${ }^{54,55}$ If clinical outcomes are definitively equivalent, the lower procedural cost of vertebroplasty may be favored over kyphoplasty. However, these trials were underpowered to detect differences in clinical outcomes, ${ }^{56}$ with KAVIAR reaching only $30 \%$ of the enrollment target.

More robust data arise from a recent large systematic review and meta-analysis comparing vertebroplasty and kyphoplasty that included 2838 patients (1454 vertebroplasty and $1384 \mathrm{ky}-$ phoplasty procedures) across 29 randomized, prospective nonrandomized, and retrospective comparative studies. ${ }^{57}$ There were no differences in back pain or disability pain scores at any time point between vertebroplasty and kyphoplasty. There was no difference in the rate of symptomatic cement leakage, but kyphoplasty was associated with a lower rate of overall cement leakage $(P<.01)$ and greater kyphosis correction $(P<.01)$. Limitations included the heterogeneity of results that probably reflects the largely nonrandomized patient cohort included. Further data are required to determine whether subgroups of patients may benefit from kyphoplasty over vertebroplasty.

\section{Hospital Admission}

Most patients admitted with a painful VCF are managed conservatively with significant resource use. In a systematic review that included 622,675 hospitalized patients with VCFs, the median length of admission was 10 days; 1 in 4 patients stayed $\geq 2$ weeks. ${ }^{58}$ Hospital mortality ranged from $0.9 \%$ to $3.5 \%$; up to $50 \%$ were discharged into a care facility. ${ }^{58}$ Moreover, 1 in 5 patients were re-admitted within 30 days. ${ }^{59}$

For hospitalized patients with VCFs, vertebroplasty is associated with a reduced hospital stay and reduced re-admission rates. An analysis of 13,624 hospitalized patients with VCFs from the French Hospital National Database demonstrated that a higher proportion of patients are discharged in 7 days after vertebroplasty compared with medical management (68\% versus $47 \%$, $P<.001) .{ }^{60}$ A large Taiwanese study using National Health Insurance data for 9238 hospitalized patients with VCFs demonstrated a 2-day-earlier discharge and lower 30-day readmission rates after vertebroplasty. ${ }^{59}$ 


\section{Mortality}

Excessive mortality risk after VCF ranges from 2\% to $42 \%$ for 12 months. ${ }^{61}$ In an analysis of the Medicare population in the United States (97,142 patients with VCF, 428,956 controls), the mortality rate for patients with VCF was twice that of matched controls. The 3 - and 5-year mortality rates for patients with VCF were $46 \%$ and $69 \%$, respectively, compared with $22 \%$ and $36 \%$ for matched controls. ${ }^{62}$ The cause of this excessive mortality is unknown. However, death may be an avoidable outcome if the etiology and predictive factors are identified. From data from the Swedish National Register of 16,051 hospitalized patients with VCF, $28 \%$ of deaths were considered causally related to the VCF. ${ }^{63}$

Vertebral augmentation also reduces in-hospital and longterm mortality after a VCF compared with medical management. In an analysis of 5766 admissions for non-neoplastic VCFs from the Nationwide Inpatient Sample, kyphoplasty halved the rate of in-hospital mortality (OR 0.52, $P=.003$ ). ${ }^{64}$ There is a similar effect on long-term mortality. In another analysis of 1,038,956 VCFs from the US Medicare dataset, 75,364 patients treated with vertebroplasty and 141,343 treated with kyphoplasty were identified. ${ }^{65}$ In the subgroup with osteoporotic VCFs who were propensity matched, the mortality risk was significantly higher after medical management compared with both kyphoplasty (adjusted hazard ratio, 1.70; 95\% CI, 1.67-1.74) and vertebroplasty (adjusted hazard ratio, 1.32; 95\% CI, 1.29-1.35); kyphoplasty had a $17 \%$ survival benefit compared with vertebroplasty (adjusted hazard ratio, 0.83; 95\% CI, 0.80-0.87).

Similar reductions in mortality after vertebral augmentation have been reported in analyses of German ${ }^{66}$ and Taiwanese health insurance data. ${ }^{47}$ In the Taiwanese dataset that identified 10,785 elderly (older than 70 years) patients hospitalized with a painful VCF, the risk of death was $39 \%$ higher in patients receiving medical management (hazard ratio, 1.39; 95\% CI, 1.09-1.78; $P=$ $.008)$ compared with vertebroplasty. Notably, the risk of respiratory failure was also higher after medical management (hazard ratio, 1.46 ; $95 \% \mathrm{CI}, 1.04-2.05 ; P=.028$ ), suggesting that pulmonary impairment may play a role in explaining the excess mortality. For patients medically managed who required opiate anesthesia, the risk of death and respiratory failure was double that of patients who underwent vertebroplasty (hazard ratio death, 1.83; 95\% CI, 1.28-2.60; $P=.001$; hazard ratio respiratory failure, $2.48 ; 95 \% \mathrm{CI}, 1.50-4.11 ; P<.001)$. These increased risks of death and respiratory failure with medical management were observed for up to 12 years of follow-up. The impressive mortality benefit demonstrated in Taiwan could relate to early intervention; 93\% received vertebroplasty within 2 weeks of hospital admission.

\section{National Organization and Medical Society Opinions}

During the past decade, there has been a clear evolution of the evidence for vertebral augmentation in the treatment of osteoporotic VCFs. At various times, national organizations and medical societies have examined the available evidence and released their recommendations, which have been variable depending on the literature examined and the respective interpretations of the available data.

In Australia, the Medical Services Advisory Committee appraises new medical procedures for public funding by examining the safety, effectiveness, and cost-effectiveness. After examining the literature between 1987 and 2004, interim public funding was recommended for vertebroplasty in $2005 .{ }^{67}$ A subsequent planned review by the Medical Services Advisory Committee was performed to include literature to August 2010. The INVEST and trials of Buchbinder et $\mathrm{al}^{23,24}$ had been published, and public funding for vertebroplasty in Australia was removed in $2011 .^{68} \mathrm{In}$ contrast, the National Institute for Health and Care Excellence, which provides evidence-based guidance and advice to the National Health Service in the United Kingdom examined the evidence to November 2011. ${ }^{69}$ In April 2013, the National Institute for Health and Care Excellence recommended vertebroplasty and kyphoplasty as treatment options for patients with severe pain after a recent osteoporotic VCF and concluded that it was reasonable to assume that vertebroplasty and kyphoplasty reduce mortality. $^{70}$

Similarly, medical societies have also varied in their interpretations of the evidence. In 2010, the American Academy of Orthopaedic Surgeons recommended against vertebroplasty, with a limited recommendation for kyphoplasty for symptomatic osteoporotic VCFs after reviewing the literature to December 2009. ${ }^{71,72}$ By comparison, in their 2014 position papers, the American Association of Neurologic Surgeons, Congress of Neurologic Surgeons, American College of Radiology, American Society of Neuroradiology, American Society of Spine Radiology, Canadian Interventional Radiology Association, Society of NeuroInterventional Surgery, and American Academy of Family Physicians considered vertebral augmentation as a valid treatment option for patients with ongoing pain or disability with medical management. ${ }^{73,74}$ The recent guideline from the Cardiovascular and Interventional Radiologic Society of Europe admits that the evidence for vertebroplasty has been conflicting, but recent data including VAPOUR show a treatment benefit. ${ }^{75}$

\section{CONCLUSIONS}

The evidence for vertebroplasty in the treatment of osteoporotic fractures has evolved with time. Early open-label trials were particularly susceptible to bias and the placebo effect, and the early sham procedure trials were designed to minimize the role of the placebo effect. However, these trials included patients with acute, subacute, and chronic fractures with moderate-to-severe pain. Across the years, evidence has shown that patients subject to more rigorous selection-those with severe pain who are treated $<6$ weeks from fracture onset-are good candidates for vertebroplasty. This has been validated by a recent methodologically rigorous sham procedure RCT. Elderly patients hospitalized for painful VCFs are a subgroup that benefits from vertebroplasty; recent data from national datasets indicate vertebroplasty results in earlier hospital discharge, lower re-admission rates, and reduced mortality.

Disclosures: Hamed Asadi-UNRELATED: Other: participated in the Interventional Neuroradiology meetings sponsored by the industry. Stefano Marcia-UNRELATED: Consultancy: Stryker, Techlamed, Vexim, Spineart. John Barr-UNRELATED: Stock/ Stock Options: Medtronic, Stryker, Comments: purchased stock. Joshua A. HirschUNRELATED: Board Membership: Codman Neurovascular, Comments: Data and Safety Monitoring Board; Consultancy: Medtronic, Globus, Comments: These companies make augmentation products.

AJNR Am J Neuroradiol 39:798-806 May 2018 www.ajnr.org 803 


\section{REFERENCES}

1. Wright NC, Looker AC, Saag KG, et al. The recent prevalence of osteoporosis and low bone mass in the United States based on bone mineral density at the femoral neck or lumbar spine. J Bone Miner Res 2014;29:2520-26 CrossRef Medline

2. Johnell O, Kanis J. Epidemiology of osteoporotic fractures. Osteoporos Int 2005;16(suppl 2):S3-7 CrossRef Medline

3. Burge R, Dawson-Hughes $\mathrm{B}$, Solomon DH, et al. Incidence and economic burden of osteoporosis-related fractures in the United States, 2005-2025. J Bone Miner Res 2007;22:465-75 CrossRef Medline

4. Gehlbach SH, Burge RT, Puleo E, et al. Hospital care of osteoporosisrelated vertebral fractures. Osteoporos Int 2003;14:53-60 CrossRef Medline

5. Ray NF, Chan JK, Thamer M, et al. Medical expenditures for the treatment of osteoporotic fractures in the United States in 1995: report from the National Osteoporosis Foundation. J Bone Miner Res 1997;12:24-35 Medline

6. Baecker N, Tomic A, Mika C, et al. Bone resorption is induced on the second day of bed rest: results of a controlled crossover trial. J Appl Physiol 2003;95:977-82 CrossRef Medline

7. Marie PJ, Kassem M. Extrinsic mechanisms involved in age-related defective bone formation. J Clin Endocrinol Metab 2011;96:600-09 CrossRef Medline

8. Kortebein P, Symons TB, Ferrando A, et al. Functional impact of $\mathbf{1 0}$ days of bed rest in healthy older adults. J Gerontol A Biol Sci Med Sci 2008;63:1076-81 CrossRef Medline

9. Venmans A, Klazen CA, Lohle PN, et al. Natural history of pain in patients with conservatively treated osteoporotic vertebral compression fractures: results from VERTOS II. AJNR Am J Neuroradiol 2012;33:519-21 CrossRef Medline

10. Jensen ME, Evans AJ, Mathis JM, et al. Percutaneous polymethylmethacrylate vertebroplasty in the treatment of osteoporotic vertebral body compression fractures: technical aspects. AJNR Am J Neuroradiol 1997;18:1897-904 Medline

11. Hochmuth K, Proschek D, Schwarz W, et al. Percutaneous vertebroplasty in the therapy of osteoporotic vertebral compression fractures: a critical review. Eur Radiol 2006;16:998-1004 CrossRef Medline

12. Bouza C, López T, Magro A, et al. Efficacy and safety of balloon kyphoplasty in the treatment of vertebral compression fractures: a systematic review. Eur Spine J 2006;15:1050-67 CrossRef Medline

13. Jensen ME, McGraw JK, Cardella JF, et al. Position statement on percutaneous vertebral augmentation: a consensus statement developed by the American Society of Interventional and Therapeutic Neuroradiology, Society of Interventional Radiology, American Association of Neurological Surgeons/Congress of Neurological Surgeons, and American Society of Spine Radiology. J Vasc Interv Radiol 2007;18:325-30 CrossRef Medline

14. Whitney CW, Von Korff M. Regression to the mean in treated versus untreated chronic pain. Pain 1992;50:281-85 CrossRef Medline

15. Turner JA, Deyo RA, Loeser JD, et al. The importance of placebo effects in pain treatment and research. JAMA 1994;271:1609-14 Medline

16. Voormolen MH, Mali WP, Lohle PN, et al. Percutaneous vertebroplasty compared with optimal pain medication treatment: shortterm clinical outcome of patients with subacute or chronic painful osteoporotic vertebral compression fractures: the VERTOS study. AJNR Am J Neuroradiol 2007;28:555-60 Medline

17. Wardlaw D, Cummings SR, Van Meirhaeghe J, et al. Efficacy and safety of balloon kyphoplasty compared with non-surgical care for vertebral compression fracture (FREE): a randomised controlled trial. Lancet 2009;373:1016-24 CrossRef Medline

18. Schulz KF, Grimes DA. Blinding in randomised trials: hiding who got what. Lancet 2002;359:696-700 CrossRef Medline

19. Boonen S, Van Meirhaeghe J, Bastian L, et al. Balloon kyphoplasty for the treatment of acute vertebral compression fractures: 2-year results from a randomized trial. J Bone Miner Res 2011;26:1627-37 CrossRef Medline

20. Van Meirhaeghe J, Bastian L, Boonen S, et al; FREE investigators. A randomized trial of balloon kyphoplasty and non-surgical management for treating acute vertebral compression fractures: vertebral body kyphosis correction and surgical parameters. Spine (Phila Pa 1976) 2013;38:971-83 CrossRef Medline

21. Rousing R, Andersen MO, Jespersen SM, et al. Percutaneous vertebroplasty compared to conservative treatment in patients with painful acute or subacute osteoporotic vertebral fractures: threemonths follow-up in a clinical randomized study. Spine 2009;34: 1349-54 CrossRef Medline

22. Rousing R, Hansen KL, Andersen MO, et al. Twelve-months follow-up in forty-nine patients with acute/semiacute osteoporotic vertebral fractures treated conservatively or with percutaneous vertebroplasty: a clinical randomized study. Spine 2010;35:478-82 CrossRef Medline

23. Buchbinder R, Osborne RH, Ebeling PR, et al. A randomized trial of vertebroplasty for painful osteoporotic vertebral fractures. $N$ Engl J Med 2009;361:557-68 CrossRef Medline

24. Kallmes DF, Comstock BA, Heagerty PJ, et al. A randomized trial of vertebroplasty for osteoporotic spinal fractures. N Engl J Med 2009; 361:569-79 CrossRef Medline

25. Saxena AP, Hirsch AE, Yoo AJ, et al. The use of advanced imaging and representation of workers compensation in vertebral augmentation: a single-center comparison with the INVEST trial. Pain Physician 2013; 16:E391-96 Medline

26. Buchbinder R, Osborne RH, Ebeling PR, et al. Efficacy and safety of vertebroplasty for treatment of painful osteoporotic vertebral fracture: a randomised controlled trial [ACTRN012605000079640]. BMC Musculoskelet Disord 2008;9:156 CrossRef Medline

27. Klazen CA, Verhaar HJ, Lampmann LE, et al. VERTOS II: percutaneous vertebroplasty versus conservative therapy in patients with painful osteoporotic vertebral compression fractures: rationale, objectives and design of a multicenter randomized controlled trial. Trials 2007;8:33 CrossRef Medline

28. Klazen CA, Lohle PN, de Vries J, et al. Vertebroplasty versus conservative treatment in acute osteoporotic vertebral compression fractures(Vertos II): an open-label randomised trial. Lancet 2010;376: 1085-92 CrossRef Medline

29. Staples MP, Kallmes DF, Comstock BA, et al. Effectiveness of vertebroplasty using individual patient data from two randomised placebo controlled trials: meta-analysis. BMJ 2011;343:d3952 CrossRef Medline

30. Farrokhi MR, Alibai E, Maghami Z. Randomized controlled trial of percutaneous vertebroplasty versus optimal medical management for the relief of pain and disability in acute osteoporotic vertebral compression fractures. J Neurosurg Spine 2011;14:561-69 CrossRef Medline

31. Blasco J, Martinez-Ferrer A, Macho J, et al. Effect of vertebroplasty on pain relief, quality of life, and the incidence of new vertebral fractures: a 12-month randomized follow-up, controlled trial. J Bone Miner Res 2012;27:1159-66 CrossRef Medline

32. Manchikanti L, Giordano J, Fellows B, et al. Placebo and nocebo in interventional pain management: a friend or a foe-or simply foes? Pain Physician 2011;14:E157-75 Medline

33. Clark W, Bird P, Gonski P, et al. Safety and Efficacy of Vertebroplasty for Acute Painful Osteoporotic Fractures (VAPOUR): a multicentre, randomised, double-blind, placebo-controlled trial. Lancet 2016;388:1408-16 CrossRef Medline

34. Hirsch JA, Chandra RV. Resurrection of evidence for vertebroplasty? Lancet 2016;388:1356-57 CrossRef Medline

35. Boszczyk B. Volume matters: a review of procedural details of two randomised controlled vertebroplasty trials of 2009. Eur Spine J 2010;19:1837-40 CrossRef Medline

36. Kaufmann TJ, Trout AT, Kallmes DF. The effects of cement volume on clinical outcomes of percutaneous vertebroplasty. AJNR Am J Neuroradiol 2006;27:1933-37 Medline 
37. $\mathrm{Fu} \mathrm{Z}, \mathrm{Hu} \mathrm{X}, \mathrm{Wu} \mathrm{Y}$, et al. Is there a dose-response relationship of cement volume with cement leakage and pain relief after vertebroplasty? Dose Response 2016;14:1559325816682867 CrossRef Medline

38. Nieuwenhuijse MJ, Bollen L, van Erkel AR, et al. Optimal intravertebral cement volume in percutaneous vertebroplasty for painful osteoporotic vertebral compression fractures. Spine 2012;37: 1747-55 CrossRef Medline

39. Wilson DJ, Owen S, Corkill RA. Facet joint injections as a means of reducing the need for vertebroplasty in insufficiency fractures of the spine. Eur Radiol 2011;21:1772-78 CrossRef Medline

40. Yang EZ, Xu JG, Huang GZ, et al. Percutaneous vertebroplasty versus conservative treatment in aged patients with acute osteoporotic vertebral compression fractures: a prospective randomized controlled clinical study. Spine 2016;41:653-60 CrossRef Medline

41. Leali PT, Solla F, Maestretti G, et al. Safety and efficacy of vertebroplasty in the treatment of osteoporotic vertebral compression fractures: a prospective multicenter international randomized controlled study. Clin Cases Miner Bone Metab 2016;13:234-36 CrossRef Medline

42. Chen D, An ZQ, Song S, et al. Percutaneous vertebroplasty compared with conservative treatment in patients with chronic painful osteoporotic spinal fractures. J Clin Neurosci 2014;21:473-77 CrossRef Medline

43. Firanescu C, Lohle PN, de Vries J, et al; VERTOS IV study group. A randomised sham controlled trial of vertebroplasty for painful acute osteoporotic vertebral fractures (VERTOS IV). Trials 2011; 12:93 CrossRef Medline

44. Hansen E, Simony A, Rousing R, et al. Vertebroplasty Compared With a Sham-procedure for Painful Acute Osteoporotic Vertebral Fractures (VOPE). https://clinicaltrials.gov/ct2/show/NCT01537770. Accessed July 16, 2017

45. Carli D. A Trial of Vertebroplasty for Painful Chronic Osteoporotic Vertebral Fractures (VERTOS V). https://clinicaltrials.gov/ct2/show/ NCT01963039. Accessed July 16, 2017

46. Baerlocher MO, Saad WE, Dariushnia S, et al; Society of Interventional Radiology Standards of Practice Committee. Quality improvement guidelines for percutaneous vertebroplasty. $J$ Vasc Interv Radiol 2014;25:165-70 CrossRef Medline

47. Lin JH, Chien LN, Tsai WL, et al. Early vertebroplasty associated with a lower risk of mortality and respiratory failure in aged patients with painful vertebral compression fractures: a populationbased cohort study in Taiwan. Spine J 2017;17:1310-18 CrossRef Medline

48. Zhan $Y$, Jiang J, Liao $\mathrm{H}$, et al. Risk factors for cement leakage after vertebroplasty or kyphoplasty: a meta-analysis of published evidence. World Neurosurg 2017;101:633-42 CrossRef Medline

49. Lindsay R, Silverman SL, Cooper C, et al. Risk of new vertebral fracture in the year following a fracture. JAMA 2001;285:320-23 CrossRef Medline

50. Anderson PA, Froyshteter AB, Tontz WL Jr. Meta-analysis of vertebral augmentation compared to conservative treatment for osteoporotic spinal fractures. J Bone Miner Res 2013;28:372-82 CrossRef Medline

51. Shi MM, Cai XZ, Lin T, et al. Is there really no benefit of vertebroplasty for osteoporotic vertebral fractures? A meta-analysis. Clin Orthop Relat Res 2012;470:2785-99 CrossRef Medline

52. Cao J, Kong L, Meng F, et al. Risk factors for new vertebral compression fractures after vertebroplasty: a meta-analysis. ANZ J Surg 2016;86:549-54 CrossRef Medline

53. Dohm M, Black CM, Dacre A, et al; KAVIAR investigators. A randomized trial comparing balloon kyphoplasty and vertebroplasty for vertebral compression fractures due to osteoporosis. AJNR Am J Neuroradiol 2014;35:2227-36 CrossRef Medline

54. Liu JT, Liao WJ, Tan WC, et al. Balloon kyphoplasty versus vertebroplasty for treatment of osteoporotic vertebral compression fracture: a prospective, comparative, and randomized clinical study. Osteoporosis Int 2010;21:359-64 CrossRef Medline
55. Evans AJ, Kip KE, Brinjikji W, et al. Randomized controlled trial of vertebroplasty versus kyphoplasty in the treatment of vertebral compression fractures. J Neurointerv Surg 2016;8:756-63 CrossRef Medline

56. Beall DP. Response to: Randomized controlled trial of vertebroplasty versus kyphoplasty in the treatment of vertebral compression fractures. J Neurointerv Surg 2016;8:763-64 CrossRef Medline

57. Gu CN, Brinjikji W, Evans AJ, et al. Outcomes of vertebroplasty compared with kyphoplasty: a systematic review and meta-analysis. J Neurointerv Surg 2016;8:636-42 CrossRef Medline

58. Ong T, Kantachuvesiri P, Sahota O, et al. Characteristics and outcomes of hospitalised patients with vertebral fragility fractures: a systematic review. Age and Aging 2017 May 10. CrossRef

59. Tsai YW, Hsiao FY, Wen YW, et al. Clinical outcomes of vertebroplasty or kyphoplasty for patients with vertebral compression fractures: a nationwide cohort study. J Am Med Dir 2013;14:41-47 CrossRef Medline

60. Maravic M, Taupin P, Roux C. Hospital burden of vertebral fractures in France: influence of vertebroplasty. Osteoporosis Int 2013; 24:2001-06 CrossRef Medline

61. Sattui SE, Saag KG. Fracture mortality: associations with epidemiology and osteoporosis treatment. Nat Rev Endocrinol 2014;10:592602 CrossRef Medline

62. Lau E, Ong K, Kurtz S, et al. Mortality following the diagnosis of a vertebral compression fracture in the Medicare population. $J$ Bone Joint Surg Am 2008;90:1479-86 CrossRef Medline

63. Kanis JA, Oden A, Johnell O, et al. Excess mortality after hospitalisation for vertebral fracture. Osteoporos Int 2004;15:108-12 CrossRef Medline

64. Zampini JM, White AP, McGuire KJ. Comparison of 5766 vertebral compression fractures treated with or without kyphoplasty. Clin Orthop Relat Res 2010;468:1773-80 CrossRef Medline

65. Edidin AA, Ong KL, Lau E, et al. Morbidity and mortality after vertebral fractures: comparison of vertebral augmentation and nonoperative management in the Medicare population. Spine 2015;40: 1228-41 CrossRef Medline

66. Lange A, Kasperk C, Alvares L, et al. Survival and cost comparison of kyphoplasty and percutaneous vertebroplasty using German claims data. Spine 2014;39:318-26 CrossRef Medline

67. Committee MSA. Vertebroplasty and kyphoplasty for the treatment of vertebral compression fracture: MSAC reference 27 Assessment report. 2005. https://www.adelaide.edu.au/ahta/pubs/ reportsmonographs/Vertebroplasty_reference_27_assessment_ report_final_printready.pdf. Accessed July 16, 2017

68. Doidge J, Merlin T, Liufu Z, et al. Review of interim funded service: vertebroplasty and new review of kyphoplasty. MSAC Application 27.1. Canberra, ACT: Commonwealth of Austrailia; 2011

69. Stevenson M, Gomersall T, Lloyd Jones M, et al. Percutaneous vertebroplasty and percutaneous balloon kyphoplasty for the treatment of osteoporotic vertebral fractures: a systematic review and cost-effectiveness analysis. Health Technol Assess 2014;18:1-290 CrossRef Medline

70. National Institute for Health and Care Excellence. NICE technology appraisal guidance TA279. Percutaneous vertebroplasty and percutaneous balloon kyphoplasty for treating osteoporotic vertebral compression fractures. April 2013. https://www.nice.org.uk/guidance/ ta279. Accessed July 16, 2017

71. McGuire R. AAOS Clinical Practice Guideline: the treatment of symptomatic osteoporotic spinal compression fractures. J Am Acad Orthop Surg 2011;19:183-84 CrossRef Medline

72. Esses SI, McGuire R, Jenkins J, et al. The treatment of symptomatic osteoporotic spinal compression fractures. J Am Acad Orthop Surg 2011;19:176-82 CrossRef Medline

73. Barr JD, Jensen ME, Hirsch JA, et al. Position statement on percutaneous vertebral augmentation: a consensus statement developed by the Society of Interventional Radiology (SIR), American Association of Neurological Surgeons (AANS) and the Congress of Neurological Surgeons (CNS), American College of 
Radiology (ACR), American Society of Neuroradiology (ASNR), American Society of Spine Radiology (ASSR), Canadian Interventional Radiology Association (CIRA), and the Society of NeuroInterventional Surgery (SNIS). J Vasc Interv Radiol 2014;25: 171-81 CrossRef Medline

74. Chandra RV, Meyers PM, Hirsch JA, et al; Society of NeuroInterven- tional Surgery. Vertebral augmentation: report of the Standards and Guidelines Committee of the Society of NeuroInterventional Surgery. J Neurointerv Surg 2014;6:7-15 CrossRef Medline

75. Tsoumakidou G, Too CW, Koch G, et al. CIRSE Guidelines on Percutaneous Vertebral Augmentation. Cardiovasc Intervent Radiol 2017;40:331-42 CrossRef Medline 